Penultimate version, forthcoming in J. Horton, U. Willems and M. Westphal (eds), The Political Theory of Modus Vivendi. Dordrecht: Springer, 2017.

\title{
CAN MODUS VIVENDI \\ SAVE LIBERALISM FROM MORALISM? \\ A CRITICAL ASSESSMENT \\ OF JOHN GRAY'S POLITICAL REALISM
}

\author{
Enzo Rossi \\ University of Amsterdam ${ }^{1}$
}

According to a familiar taxonomy, when it comes to justifying liberalism, we are faced with a camp roughly divided in two: on the one side we have teleological liberals, who defend liberalism as a conception of the good, i.e. as a way of life whose substantive values are the best available to us. On the other side we find deontological liberals, who defend liberalism as a conception of the right, the idea being that liberalism's appeal consists mainly in its ability to arbitrate conflicts and generate a consensus between conceptions of the good through a theory of rights and justice. That distinction becomes particularly salient when we are confronted with the issue of how liberalism could and should cope with ethical diversity. More importantly, it is about this issue that both conceptions of liberalism have faced some of the most penetrating critiques. In this essay I characterise and assess a third way to ground liberalism, and in particular liberal toleration, namely through the idea of a modus vivendi (hereinafter MV). As I will show, this third approachexemplified in John Gray's work-can be seen as one way to develop the new realist programme in political theory. ${ }^{2}$

The term 'modus vivendi' has acquired some currency in contemporary political philosophy through the (rather derogative) use Rawls makes of it in Political Liberalism: "A consensus on accepting certain authorities, or on complying with certain institutional arrangements, founded on a convergence of self- or group interests." ${ }^{3}$ Roughly, and with some qualifications that I will formulate below, that is also the sense I have in mind here. What is important to note for now is that $\mathrm{MV}$, unlike the theories of justice that have come to

\footnotetext{
1 Department of Political Science, Roeterseiland Campus, Po.box 15578, 1001NB Amsterdam, The Netherlands.E.Rossi@UvA.nl.

2 For overviews of this current see Galston (2010) and Rossi \& Sleat(2014). I discuss different aspects of the relation between MV and realism in Rossi $(2010,2013)$.

${ }^{3}$ Rawls (1993, 147 Rawls dismisses the idea of grounding liberalism in a 'mere MV' because a MV, unlike the kind of settlement he terms 'overlapping consensus', does not enjoy the moral allegiance of all involved parties.
} 
constitute the dominant paradigm of recent political philosophy, is not (directly) a blueprint for the design of institutions, policies, and the like. Those theories spell out a set of evaluative criteria describing an ideal political model, and evaluate existing polities in accordance to their conformity to such model. Typically, it turns out that (one form of) liberalism is the only set of political norms that satisfies these criteria in full, or to the required degree. As I said, this combination of liberalism as a normative political theory-a set of political norms - and of its traditional justifications - a set of evaluative criteria-may lead some to think that in liberal theory there is no salient distinction between the evaluative and the normative level, in the sense that one particular set of evaluative criteria generates just one ideal set of norms. That seems true of both the deontological and the teleological traditional justifications of liberalism. However, while it is true that the evaluative level informs and shapes the normative level to some degree, the connection need not be one of strict entailment. In fact, here I rely on John Gray's work to show that MV, while also a teleological theory, can be formulated as a more open-ended evaluative criterion (we will see later in what sense it is 'open-ended'), rather than an ideal blueprint to be followed and approximated. More importantly, I shall argue that this evaluative criterion can be deployed as a justification for liberalism that, at least because of the way it can deal with the problem of diversity, is preferable to the more orthodox deontological or teleological justificatory strategies. ${ }^{4}$ But that is not good news for liberalism, for I will also argue that grounding liberal political authority in a MV undermines liberalism's aspiration to occupy a privileged normative position vis-à-vis other kinds of regimes. So MV can save liberalism from moralism, but at cost many liberals will not be prepared to pay.

To reach that conclusion I shall proceed in the following way. First I discuss the problem of diversity and the traditional responses to it (section I); I shall then present some arguments as to why the traditional justifications of liberalism cannot adequately deal with this problem, and introduce the idea of MV as a way of overcoming this difficulty (section II). In section III I sketch a line of defence of the project of MV against a common objection and present my overall assessment of MV-grounded liberalism.

\footnotetext{
${ }^{4}$ To date, among the most articulate defences of the project of grounding liberalism in a MV is the one John Gray developed in a number of recent writings (1996, chs 2 and 6; 2000a; 2000b), which will indeed feature prominently in my analysis. Other promising defences of modus vivendi have been put forward by David McCabe (2010), John Horton (2006, 2010), and Patrick Neal (1997). Claudia Mills (2000), Bernard P. Dauenhauer (2000), and Scott Hershowitz (2000) defended the idea of modus vivendi more narrowly, against Rawls' reservations.
} 
Let us start by asking what it may mean that a normative political theory is superior in dealing with the problem of ethical diversity, and why that is important. What I have in mind here is not the idea, as common as unargued for in much recent literature, that a theory should aim at being inclusive towards ethical diversity. To say that a high level of inclusiveness constitutes a virtue of a normative political theory is a plausible claim, but it needs further argument: why should ethical diversity be desirable, or, for that matter, even admissible? There is no direct inference from the empirical acknowledgment of the fact of diversity to the normative advocacy of toleration. A normative political theory deals with the problem of ethical diversity by explaining what features (if any) of the fact of ethical disagreement call for its accommodation, and by providing evaluative criteria that follow from or are consistent with such explanation (Rossi, 2008: 11-16).

We can now begin to look at how the traditional justifications deal with this problem. Gray argues that there is a mainstream in the way liberalism understands its justificatory status: "liberal toleration is the ideal of a consensus on the best way of life." ${ }^{5}$ However, he argues, this view does not occupy the whole of the logical space available for the justification of liberal political institutions and practices. There is a second justificatory possibility: "the belief that human beings can flourish in many ways of life", whereby liberalism becomes "the search for terms of peace among different ways of life" (Gray 2000: 1-2). Gray does not think that this second justificatory strategy has been confined to logical space throughout the history of political thought. He argues that it is present, even though perhaps just in nuce, in the writings of Hobbes, Hume, and more recently of Isaiah Berlin and Michael Oakeshott. However he also holds that these writers have exercised only a very limited influence on the development of liberal political philosophy. As we shall see, it is this second view (or 'face' of liberalism, as Gray puts it) that informs the idea of MV.

Before analysing the dichotomy further, it is worth highlighting its affinities with the distinction between realism and moralism drawn by Bernard Williams (2005), and between realist and 'ethics first' political philosophy as conceived by Raymond Geuss (2008). The general thought common to all three thinkers - as well as to most contemporary realists-here is that coercive political orders cannot or at any rate should not be structured on the basis of pre-political moral commitments, i.e. commitments that float free of the practice of politics itself. ${ }^{6}$

\footnotetext{
5 Gray 2000: 1.

${ }^{6}$ On this distinction see Jubb \& Rossi (2015).
} 
Also notice that Gray's dicothomy is about the justificatory status of a normative position, not about the normative position as such: what is being contested is not liberalism as a set of norms, but one way of justifying it, namely the reliance arguments that liberalism and liberal toleration are desirable because they are best and most rational form of life available to human beings. Now recall the familiar distinction between deontological and teleological liberalism. Both justificatory strategies can be analysed as responses to the problem of diversity. ${ }^{7}$ What is more, perhaps one of the most salient ways of characterizing the differences between them is to consider the differences in their answer to the problem of diversity. So it is strikingly odd that, in Gray's distinction between the two faces of liberalism, both strategies are labelled in the same way; that they both fall under the umbrella of the project that grounds liberalism in a rational consensus on the best way of life.

One can see how this label could be applied to (certain forms of) teleological liberalism: consider for example the view that liberalism is best justified on the basis of a certain interpretation of the value of autonomy. The idea here would be that liberalism is justified because it enables us to live autonomous lives (such a position would of course then need the support of an argument as to why we should value autonomy, and so on). In Gray's terminology, on this teleological view we would consent to liberalism because it enables us to live autonomously, i.e. to live the best possible life.

What about deontological liberalism? These theories present their position as a sort of non-substantive metatheory, which looks much more like the second face of liberalism described by Gray. This is particularely true of neutralism, the predominant model of deontological liberalism. ${ }^{8}$ Roughly this justificatory paradigm is based on the idea that giving priority to the right over the good will allow us to bracket conflicts among goods or interests, as it were. The main advantage of this strategy would be that the resulting normative principles

\footnotetext{
7 This is not to say, of course, that it is only possible to conceptually make sense of them in the light of that problem; neither is it to say that they are to be understood primarily as responses to that problem -even though for deontological liberalism this is probably the case.

8 Another reason for doing so is that Gray explicitly attacks neutrality as the dominant paradigm in his $2000 \mathrm{~b}$, and highlights its tight connection to deontological liberalism; however, the words 'neutrality', 'neutralism' or 'neutralistic' are not even present in the index of 2000a. This is strange, because to a large extent 2000 a presents a more articulated version of the arguments outlined in 2000b. I take it however that when Gray, in 2000a, refers to 'legalistic' liberalism he has in mind what is generally termed 'neutralism', as this remark (among many) also confirms: "The shift from toleration of evils to neutrality regarding the good is such a shift. It has gone with an ambitious programme of reconstructing liberalism as a project in the philosophy of right. It is not by accident that the notion of neutrality has been associated with deontic liberalism." (2000b: 326)
} 
would be equally binding independently of agents' different conceptions of the good. It doesn't matter, then, whether those principles are at odds with the conception of the good of some of the agents they place under obligation, because morality, crudely, has nothing to do with the good, or with what we see as being our good. It is in this sense that the theory is neutral with regard to our conceptions of the good: the emphasis on the neutrality ostensibly implied by deontology is a way of presenting the advantages of deontology in an ethically fragmented environment. More to the point of our discussion, this emphasis on neutrality provides the grounding of toleration for the deontological justification of liberalism. This idea is, by and large, an offspring of the Kantian project of constructing morality as a pure philosophy of right. ${ }^{9}$

For now, however, let us just try to very briefly get a sense of how, from Gray's perspective, it is possible to claim that this neutralistic brand of liberalism belongs to the traditional value-laden face of liberalism, despite its apparent committment to securing a set of norms that is immune to the demands of conflicting goods and conceptions of the good. The key to this claim can be found if we look at the sort of normative theory we obtain by giving priority to the right, i.e. a theory of justice, which adjudicates the conflicting demands of a multiplicity of goods and interests through the vindication of a set of rights. Now Gray's contention is that in doing so these theories fail to deliver the priority of the right they are after, for the idea of justice is, as it were, an empty box if we do not understand the rights it embodies as protecting particular values, goods or interests. ${ }^{10}$

The proposal that principles of neutrality or equality are constitutive or foundational in liberal morality, rather than any conception of the good, breaks down on the demonstration that such principles acquire a content only by way of substantive judgements about human well-being. We cannot resolve conflicts between the demands of different rights unless we can give weights to the interests they protect and promote. [...] That the good is prior to the right is not a substantive objection to any specific liberal theory

\footnotetext{
9 Charles Larmore (1996) has shown how the project of Kantian deontology can be understood as a response to the fragmentation of the good (Ch. 1). He also traces some of the connections between this project and the ideal of liberal neutrality (Chs. 6 and 7).

${ }^{10}$ The point is not that pursuing justice equals to pursuing a conception of the good, becaue the citizens unite in the pursuit of a justice as a goal or an ideal. In a sense, Ralws is right in saying that there is a difference between pursuing justice and pursuing a conception of the good (1993: 146n). Justice, as a concept (or goal, or ideal), is neutral with respect to conceptions of the good. The probem, however, is that each conception of justice (such as Rawls' own 'justice as fairness', or Nozick's libertarianism, etc.) will inevitably give priority to a set of goods and interests over others.
} 
of rights. It is a necessary truth regarding all discourse about rights. ${ }^{11}$

This becomes most evident when there is a dispute in a judicial review board such as the US Supreme Court as to what are the normative implications of a certain constitutionally established right: the dispute boils down to a disagreement about exactly what interests or goods the right at stake should protect. ${ }^{12}$ Controversial as it may be, this line of argument against neutrality is both familiar and (at least) plausible, as it relies on the well-known interest theory of rights. Assessing the merits of this theory would be beside the focus of this paper. ${ }^{13}$ Thus we can grant Gray this point, in order to be able to move on and see where his broader view is headed. Before we do so, however, it may be worthwile to add just one observation about the background assumptions of Gray's political philosophy. It is not by chance that Gray has come to rely on the interest-theory of rights. Just as this theory is based on the assumption that the driving concern of normative political philosophy is a concern for human well-being (broadly conceived), so is Gray's overall project. Again, it is not possible to discuss this assumption here; however I trust that it is possible to proceed on this assumption without begging too many questions. After all, it is just the idea that political philosophy is about what sort of political arrarangements can enable us to live a good life in society.

In sum, if we are willing to follow Gray's line of argument, we have established that the familiar distinction between deontological and teleological liberalism we started out with is somewhat misleading (at least for the purposes of this essay), for both traditional justificatory strategies cannot help being committed to the advancement of particular, substantial goods, values or interests. ${ }^{14}$ They either do it

\footnotetext{
11 (Gray 2000b: 326-27)

${ }^{12} \mathrm{It}$ is in this sense that Gray describes neutralistic liberalism as 'legalistic'. For a discussion of how rights that supposedly settle conflicts between interests are (sometimes) not capable of doing so because of the fact that they themselves embody some such interests can be found in the jurisprudential work of Jeremy Waldron (1999, esp. part 3). The tradition of American Legal Realism advances similar contentions (Leiter 2005), so much so that a systematic study of its connection with the new political realism is now overdue.

13 Will Kymlicka has shown that Rawls' attempt to give priority to the right by promoting equal liberty and distribution of primary goods boils down to a position on what best promotes the good of citizens: “...Equal liberty and the distribution of primary goods are the most appropriate conditions for promoting our essential interest [...] Rawls and a perfectionist do not disagreee over the relative priority of the right and the good. They just disagree over how best to define and promote people's good." (1989: 35).

${ }^{14}$ I employ terms like 'goods', 'values' and 'interests' as what one might call 'rough synonims': there are differences between them that I am of course willing to acknowledge, but as far as my arguments are concerned, these differences can safely be ignored. Suffice it to say that a value, good
} 
directly (as with traditional teleological liberalism's endorsement of, say, autonomy), or indirectly (as with the promotion of a set of goods through a conception of justice), but the underlying pattern is the same, as far as we are concerned here. It is in this sense that we can speak, with Gray, of one traditional 'face' of liberalism. Whith that in mind, we can return to our original question and consider how this traditional approach fares as a response to the problem of diversity. As we shall see, Gray's contention is that, no matter what particular value or set of values inform our justificatory efforts, there will always be an important sense in which the traditional approach to the justification of liberalism fails to address the problem of diversity.

\section{II}

In order to see what (if anything) is wrong with the traditional, value-laden face of liberalism we need to consider what philosophical explanation of the fact of disagreement about the good it can provide, and how its evaluative criteria relate to it. Gray's idea is that, fundamentally, all traditional justifications of liberalism share the same strategy of response to the fact of ethical diversity: they do not take it seriously enough. To some extent, they all consider the fact of disagreement about value a superficial phenomenon of our experience, and ultimately all seek to explain it away and/or bypass it by appealing to a ranking of those values, a ranking informed by the value or by the set of values that consistutes the teleological kernel of their preferred version of liberalism (e.g. utility, autonomy, self-ownership, or the set of values and interests protected by any given conception of justice). Now the interesting question is whether it is actually possible to provide a well-grounded, uncontroversial account of value that plausibly supports (always) giving priority to this teleological kernel. Gray holds that this is not possible. On the contrary, for him values are irreducibly plural, conflicting, and, more importantly, incommensurable.

The 'purality of values' is not a metaphysical point about the numerical identity of values. This, as Ruth Chang observed, is an issue we can safely ignore if we are interested in the nature of values for purposes of normative theory. ${ }^{15}$ So Gray just means that our experience presents us with many conflicting value-bearing options.

As for incommensurability, this notion, which would be probably better described with the term 'incomparability', indicates that often in important deliberative scenarios we are

or interest is something that provides a reason for action (the kind of reason-pro tanto, internal, external, etc.-depends on the general account of value we choose to employ.

${ }^{15}$ Chang 2001. The idea here is that, for the purposes of practical reason, conflict about values can indifferently be explained as a clash of different values (e.g. liberty vs. equality), or of different aspects of the same value (e.g. happiness). 
not able to individuate a rational procedure for producing a ranking of those value-bearing options (let us conventionally call the countrary view 'monism'). ${ }^{16}$ Incomparability, combined with the fact that those options are also often incompatible, causes many contradictory propositions about value to be true at the same time (e.g. ' $x$ is good for me now' and ' $x$ is not good for me now'). Gray is adamant about this: "Again, to say that there are incommensurable values does not mean that the only way we can test our ethical beliefs is by assessing their consistency with one another. Indeed it is to say virtually the opposite. [...] Consistency is not an overriding virtue in ethics." ${ }^{17}$ Now how can a normative theory be consistent with this view about value that allows for contradictions? It cannot. The normative outcome (if we may call it so) generated by such a view of value is 'anything goes', to put it crudely.

Before we move on to see how this value pluralism is connected to the idea of MV, let us consider on what grounds we can argue that this view of value is preferable to the monistic views that inform the traditional justifications of liberalism. The main argument for the preferability of value pluralism that can be extracted from Gray's writings is the argument that value pluralism is, among the many accounts of the nature of value that are available to us, arguably the one that most closely matches our perception of the workings of ethical life, i.e. our daily experience of conflict and disagreement. ${ }^{18}$ As we have seen when we characterized the problem of diversity, we should beware from leaping from a fact about the world such as that of ethical disagreement, to assuming the truth of the value-judgements that participate in the disagreement. However, it also seems plausible to hold that the burden of proof is on those who, like the monists, defend the view that is most distant from the phenomenology of our moral experience. And in fact monistic arguments usually do not do a very good job of explaining (away) these phenomena. Despite this, the pluralistic view of value may still seem implausible to many. To mitigate this possible reaction, consider that pluralism need not be taken as a view about the objective nature of value. We can also understand it just as a form of epistemological prudence or moderation: a way of taking our disagreement about the good seriously and of

16 On the distinction (and the frequent confusion) between inccommensurability and incomparability, see Chang 1997, "Introduction" (The point is that incommensurability occurs when we cannot put two values on the same scale; but that is not a necessary condition for a comparison to take place). How often we actually encounter such hard cases is something that Gray does not address; however a realistic assessment of this could give us a better sense of the relevance of the issue of incomparability. However, in general it seems at least plausible to say that such conflicts are rather common in our everyday experience.

${ }^{17}$ Gray 2000a: 41.

18 Gray writes that "questions of value are answered at the bar of experience" (2000a: 64). 
suspending our judgment about the various, competing explanations of the fact of ethical diversity. This need not be a strong form of scepticism, of the kind that denies the possibility of us ever being able to know how to rank (some) value-bearing options. ${ }^{19}$ The idea is just that, right now, this ranking task presents us with some serious difficulties. Even this weaker form of scepticism is controversial in its own rigtht; however it seems at least less controversial than the stronger version, and than any fully-fledged monistic view of value. In any case, we can go along wiht Gray's pluralism for now, if only to move on to see what conclusions it yields.

Now, in the light of value pluralism, what exactly is the problem with the traditional justifications? Unlike what one may think, the problem is not with their normative narrowness, for no prescription of inclusiveness follows from such a radically pluralistic view of value: if instances of values are incomparable, we are unable to tell whether it is preferable to have, within a society, a large sampling of many (mutually incomparable) values, or a larger amount of fewer of those values. So, when Gray complains about liberalism being a 'monoculture', he cannot (consistently) be using the familiar argument against liberalism from value pluralism, which claims that liberalism as a set of political institutions and practices is too narrow, not inclusive and tolerant enough (from a normative point of view). ${ }^{20}$ The problem with those 'monocultures' is rather at the level of their philosophical self-understanding, insofar as they claim to be more legitimate than (all) other regimes that privilege other values. ${ }^{21}$ More precisely, it is not that no regime can claim more legitimacy than any other; the point is on what grounds they do so. Liberalism's traditional grounds, such as (say) a Kantian understanding of rights

${ }^{19}$ It is not clear whether Gray understands his value pluralism as a theory about the objective nature of value (that, for example, is clearly his interpretation of Berlin's pluralism, which he uses in some of his own arguments as well), or as an epistemological idea. However some of his passing remarks, and most explicitly those in the final paragraphs of Two Faces of Liberalism, point towards such a sceptical interpretation of MV: "It would be idle to deny that modus vivendi is a sceptical view."(2000a: 139)

${ }^{20}$ For a now almost classic formulation of this view, see Crowder 1994. A similar position had been taken before by John Kekes and by Gray himself (in a previous, anti-liberal phase).

${ }^{21}$ Gray does acknowledge that not all liberals are committed to full-scale temporal and geographical universalism. However he also holds that even the more particularistic liberals such as Raz tend to be committed to the view that, in some contexts, liberal values are necessarily to be raked before non-liberal ones. This is because those particularistic liberals rely on empirical assumptions about the better 'performance' (in delivering wellbeing) of liberal values in certain societies, or on a philosophy of history that conceives of liberalism as the definitive etic for a certain historical context or for a certain stage in the moral evolution of humankind. Gray then argues that those empirical assumptions do not hold in the face of, say, the success of illiberal Asian values in capitalistic Western societies. $\mathrm{He}$ also dismisses philosophies of history that sanction the necessary priority of liberal values in certain contexts. 
and/or an Enlightenment philosophy of history are not good grounds: on the pluralistic view of value, taken per se these grounds embody values as controversial as those of many other cultures. $^{22}$

Let us now return to the 'anything goes' we extracted from Gray's value pluralism, in order to see what we can or should make of it. Actually Gray argues that, as a matter of fact, it turns out that not exactly anything goes: there are some interests that all humans happen to have in common, because they are essential for the pursuit of any worthwile human existence. ${ }^{23}$ And to these goods or interests correspond some rights. A set of minimal, basic human rights that require protection. Note that this is not a form of backdoor monism. It is just an empirical matter, Gray claims, that people happen to have these interests in common; more importantly, even these fundamental goods can conflict with one another, hence there is no system of rights where all those values are protected to the same degree or 'fairly'. Therefore, even though we may call the rights protecting those basic interests 'universal rights' if we so fancy, they are not universal in the traditional sense of the term, for they are not entirely contextindependent: "Human rights are not immutable truths, freestanding moral absolutes whose contents are self-evident. They are conventions, whose concerns vary as circumstances and human interests vary". ${ }^{24}$ In different contexts we understand our basic interests differently, we choose different trade-offs between them, and we develop different ways of protecting them.

And this is where the idea of MV comes into play: a MV is a settlement, achieved between the competing demands of the values and interests of the different actors that make up our societies, in which our basic rights are protected. Clearly, for this to be possible, we will need a condition of peaceful coexistence (or absence of violence), which could also be cashed out as another basic human right. There is no universal recipe for achieving a $M V{ }^{25}$ The ways of pursuing peace are

\footnotetext{
22 So notice the difference between Gray's position and David McCabe's, the other prominent attempt to ground modus vivendi liberalism in value pluralism. McCabe defends a form of "pluralist perfectionism" (2010: 116), and so he does not shy away from embracing a robust conception of personal autonomy as the link between pluralism and modus vivendi liberalism. Whatever the merits of this position, it should be quite clear that its expressly moral character will not appeal to realists, so discussing it at length would take us far from this paper's topic.

23 It is not clear whether Gray understands these as merely negative interests (universal evils), or also positive ones.

24 Gray 2000a: 106.

25 What is more, depending on how much weight we want to put on the context-dependence of the way we understand our basic interests, it is not even certain that it will always be possible to achieve a MV: some group may construe its basic interests as incompatible with those of some other group. It seems however plausible to assume that these will be rather rare cases.
} 
open too, because they depend on how we understand our basic rights: "human rights are convenient articles of peace, whereby individuals and communities with conflicting values and interests may consent to coexist." 26

At this point one might ask: if MV consists in a political theory of 'anything goes' (provided that peace and protection of basic rights are granted), why not be satisfied with liberalism? Certainly liberal regimes satisfy these conditions, one may go on to argue (as a matter of fact, if Gray's analysis is correct, then a MV is already in place in most decent societies). But that would be a wrong reaction to the proposal of MV, for it would consider it as a normative proposal, whereas it is a merely justificatory one. Again, MV doesn't want to change liberalism as a set of norms, but just the way we justify it. Liberal legislation should not prescribe things very different from those it currently prescribes. Liberals should rather change the language by which they support their prescriptions -recall that our whole discussion is about justifications, not norms. They should drop the language of justice, rights, or of the universal appeal of (say) the value of autonomy (for the pluralist view of value forbids to appeal to such robust views of value), and adopt the language of MV, i.e. of justifying political institutions as the best deal that can be struck between competing interests and conceptions of the good.

Before we move on to the next section, some general clarifications. We have seen that Gray's value pluralism can be understood as a sceptical, perhaps antitheoretical position. It does not do any work towards a direct justification of MV, because it cannot justify any normative political theory. It cannot entail it, and not even be consistent with any such theory. The work it does it just that of undermining the traditional justifications for liberalism (and presusumably for most other normative political theories, but that is beyond the focus of this paper). So what pluralism does instead is to 'clear the ground' for MV: given that Gray's value pluralism shows that no normative theory can be consistent with the correct understanding of value (for such understanding comprises true contradictory value judgements), there is nothing wrong with saying that 'anything goes'. But then why is it that value pluralism does not also undermine the particular political institutions and norms protecting our basic rights in any given MV? The answer to this should become clear if we realise that the kind of justification provided by MV is different from that of the traditional justificatory strategies. As we have seen, the traditional strategies ground political norms by showing how they follow from the value or the set of values that constitute their teleological kernel. So, for example, an autonomy-based teleological foundation of liberalism would justify a norm protecting freedom of religion, because in order to honour the

${ }^{26}$ Gray 2000a: 105. 
value of autonomy we need to allow individuals to freely choose between different religious views. Justification through $\mathrm{MV}$, on the other hand, does not proceed in this deductive way. Rather, it is a way, for those subject to the political authority of the MV, of making sense of why they have come to a certain setllement, of what interests it protects and what purposes it serves, and so on. The idea is then that most people most of the time are expected to converge on the minimal view that protecting a set of basic human rights is in their best interest. This should not be taken as a way of relativizing the justification of political norms, or of giving up normativity and retreating to some sort of hermeneutic selfunderstanding. This type of justificatory approach aims to enable the subjects of political authority to evaluate how the political system serves their purposes, and hence whether they have reason to (continue to) consent to it.

\section{III}

So far we have seen how MV is connected to a pluralistic account of value and what sorts of normative committments it generates. Now at least two important questions remain open. The first one is the main question this paper is meant to answer: can MV be used as a justificatory strategy for liberalism? It should be clear by now that on Gray's view, in the contexts where it will not be possible to achieve a MV through liberal norms and institutions, the settlement that we will manage to get will still be justified. Considering and challenging this last point is thus crucial. The second question concerns the moral status of MV. Some critics of MV have argued that if we accept $\mathrm{MV}$ as a criterion for political legitimacy, we will end up bestowing approval upon morally inacceptable regimes. In a sense, this second worry is more serious than the first one: if not dealt with adequately, it will cast a shadow of (possible) moral blameworthiness on the project of MV, which would arguably make it futile to bother asking whether it is compatible with liberalism or other regimes. ${ }^{27}$

We start, then, from the worry about morality. We have just seen that Gray's view of value (or at least a plausible interpretation of it) commits him to a sceptical or antitheoretical position. 'Anything goes', provided that protection of basic rights and peaceful coexistence are granted. ${ }^{28}$ Perhaps those who attacked this view as immoral

\footnotetext{
${ }^{27}$ That is not because I think that liberalism is by definition immune from charges of immorality; rather, because I maintain that a morally unsatisfactory version of liberalism is not worth pursuing.

28 At this point one may worry, as George Crowder has done even for Gray's less teleologically-articulated version of MV (2002: 121-122), that this way of presenting MV risks of focusing too much on peaceful coexistence and protection of universal values as a set of goals, thus making MV not very different from the traditional forms of teleological liberalism it is supposed to overcome. Indeed, surely MV is a teleological
} 
should have said that it is amoral, not immoral; to accuse MV of immorality is besides the point, and in a sense begs the question, for it presupposes a view of value that is compatible with a broadly Kantian view of morality, and thus fails to take into account the peculiarity of the view of value that informs MV.

The moralistic critics claim that $\mathrm{MV}$ is often likely to legitimise unjust or unfair political settlements. From their perspective this is due to the fact that MV does not contemplate any neutral, fair procedure for the adjudication of conflicts between goods and interests. But the problem with this criticism seems to be that Gray's view of value tells us that there is no way that morality, or 'rights', or 'justice' can solve conflicts between our goods and interests. He is not trading morality against something else, such as peace; rather, he is saying that we cannot use morality (in the strict Kantian sense) when trying to settle conflicts about what is valuable to us. This point notably mirrors Raymond Geuss' realist remark that "Ethics is usually dead politics: the hand of a victor in some past conflict reaching out to try to extend its grip to the present and the future." (2010: 42). ${ }^{29}$

It will not do to reply, as some may want to do on Gray's behalf, that MV is at least committed to the protection of basic needs or interests, and that is all morality is about, whereas all other goods, values and interests are morally indifferent preferences. This would be an odd line to take, and not even one that fits in the framework of Gray's view of value. Moral minimalism will not satisfy the moralist. Besides, and more importantly, it seems to me that it is incorrect to refer to this core of basic interests as 'morality': in Gray's view it is just a core of interests that all humans happen to share (and which also tend to be understood and protected in different ways in different contexts). The point is that there is nothing 'moral' about this, at least not 'moral' in the Kantian sense: these rights are conceived as reflecting a set of interests and goods, and not as a set of duties determined a priori as ways of (allegedly fairly) adjudicating the demands of

theory, as Gray himself notes (2000a: ?). Now the interesting question is whether there are any significant differences in the structure of MV's teleology, as opposed to that of the traditional teleological justifications of liberalism. It seems to me that there is at least one rather significant difference. In brief: unlike (say) utility for a classical utilitarian, peaceful coexistence and protection of basic rights for the advocate of MV are not a goal that is set ex ante, independently of any other considerations. That is to say that, whereas for a utilitarian in any possible world there will be a way of maximizing utility (at least in principle), a MV will not necessarily obtain. The feasibility of its goals is not decided ex ante, but is dependent on whether the parties in conflict actually happen to share enough common ground to be willing to engage in a MV. It is this contingency of its goals that differentiates MV from traditional teleology. In Gray's own words, "The end of modus vivendi is not some supreme good -even peace. It is reconciling conflicting goods.” (2000a: 25).

${ }^{29}$ I expand on this issue in Rossi (2016). 
conflicting goods and interests. The fact that we have these interests then generates duties (in fact Gray says that these goods/interests must be protected by corresponding rights), but it is clear that here the right is subordinated to the good, and in a strict Kantian sense this is not what morality is about.

It would be however unfair, on the basis of this point, to claim that MV is devoid of ethical content. There is room in MV for Aristotelian goodness(es), even though there is little or no room for Kantian morality. It is not that MV recognizes the possibility of morality and yet decides to ignore it. The point is rather that, on the radically pluralist view of value at the basis of $\mathrm{MV}$, there is no room for morality when conflicts between goods are at stake (and that, especially in the realm of politics, is a permanent condition). The moralist would have us adjudicate conflicts between goods through a conception of the right, but that option is simply not available to us if we accept a pluralist account of value. In other words, the moralist blames the (realist) pluralist for their failure to deliver fairness in the arbitration of conflicts between goods and interests; but the pluralist denies that this is a feasible goal: what the moralist calls a 'fair' outcome is to the pluralist just a rather arbitrary advancement of one particular set of goods and interests over others. Thus if the moralist wants to challenge the pluralist on this terrain, she needs to show why one should give up the pluralist understanding of value in the first place. This understanding of value may very well be controversial; on the other hand, it is far from clear that the view of value presupposed by the moralistic critic of $\mathrm{MV}$ is any more compelling. There is at least a battle the moralist needs to fight here.

Those impressionistic remarks fall short of completely removing the worry about the moral status of MV. However, adequately following the line of argument I have sketched would lead us far way from the issues under consideration here, so for our present purposes it will have to remain a tentative suggestion. More importantly, the line of argument I suggested is not the only available if we want to defend MV from the charge of immorality, and arguably not even the most effective one. I chose to focus on it simply because (to my knowledge) it is not present in the literature. ${ }^{30}$

\footnotetext{
30 For a different and more effective defense, see for example Horton 2006: "Even when we have felt pressurised and agreed reluctantly to do something, we often still think ourselves bound so to act [...] Modus vivendi contains within it the idea that the resulting political accommodation or settlement is in some sense 'acceptable' to the parties to it: it is not the ruthlessly, coercive imposition of a particular set of arrangements by one party or another.". This move anticipates what Bernard Williams (2005) calls the realist 'basic legitimation demand'. For illuminating discussions of this notion see Hall (2013), Sagar (2014). It is also worth pointing out how the role of Williams' 'critical theory principle' within his account of legitimacy tends to be played down by his liberal interpreters, and by liberal realists more generally.
} 
Let us now turn to the issue of whether MV can be deployed as a normative justification of liberalism. As I anticipated, it seems that if we want to use Gray's formulation of MV, we cannot deploy it. The problem is that, in Gray's theory, MV works as a mere treshold requirement for justification: once the minimal conditions of peaceful coexistence and protection of basic rights are met (and this is certainly possible to achieve even in very illiberal regimes), Gray's conception of MV turns a blind eye to the differences between liberal and non-liberal polities. Thus liberalism ends up on a justificatory par with other regimes. And that is a problem if we want to use MV as a foundation for liberalism. It is a problem not in the sense that it makes libearalism less legitimate per se: liberal political systems may very often turn out to be justifiable as a MV (I actually struggle to imagine a version of liberalism that does not qualify as a MV). The worry is rather that it leaves us in a situation whereby, if some nonliberals want to overthrow a liberal regime, we cannot object (provided that the non-liberals can show that their position satisfies the requirements of MV). So Gray's conception of MV cannot be presented as a revival of the project of liberalism, for not only it is unable to show why liberalism should be preferable to other regimes, but it even fails to adequately defend liberal regimes that are already in place. ${ }^{31}$ What is more, even if we can establish that liberalism is the best MV in a certain place ar a given time, we cannot rule out the possibility that, in the future, a better political arrangement will be devised. It is in fact in this sense that MV, as I said at the beginning, is an open-ended teleological theory: it does not claim to entail an account of what normative principles will always perform better in mediating conflicts between goods and interests and in delivering well-being in any given context, or even in one particular context.

So it is clear that, even on this qualified version of the idea of MV, liberalism needs to give up more than just its traditional universalistic aspirations. It needs to give up its own self-understanding as a normatively privileged position vis-à-vis other ideologies. Now, liberal realists (Jubb 2015, Sabl 2017, Sleat 2013) are typically happy to acknowledge the contingency of their view relative to liberal moralism. But the present reading of Gray suggests that this contingency-at least insofar as liberal realism is tied to the idea of MV-goes further than most liberals' comfort zone. That may take realism, or at least $\mathrm{MV}$, beyond liberalism and in both conservative and radical directions. ${ }^{32}$ As for liberalism itself,

\footnotetext{
${ }^{31}$ Both George Crowder (2002) and Glen Newey (2001), for example, have argued that MV cannot qualify as a liberal position, on grounds that could be reduced to the argument I presented here.

32 To my knowledge, traditional conservative realism has not been developed systematically in contemporary political philosophy. For the radical tendency see Prinz (2015), Prinz and Rossi (2017), Raekstad (2016), Rossi (2015).
} 
this essay may just have shown quite how literally we should take the old jibe that a liberal is someone who cannot take their own side in an argument. ${ }^{33}$

\section{References}

Chang, Ruth (ed.) (1997). Incommensurability, Incomparability, and Practical Reason. Cambridge, MA: Harvard University Press.

Chang, Ruth (2001). "Value Pluralism". International Encyclopedia of the Social and Behavioral Sciences, XXIV: 16139-16145.

Crowder, George. (1994). "Pluralism and Liberalism". Political Studies, 42: 293-305.

Crowder, George (2002). Liberalism and Value Pluralism. London and New York: Continuum.

Davion, Victoria, and Clark Wolfe (eds.) (2000). The Idea of a Political Liberalism. Essays on Rawls. New York: Rowman \& Littlefield.

Galston, William A., 2010. Realism in political theory. European Journal of Political Theory, 9: 385-411.

Geuss, Raymond (2008). Philosophy and Real Politics. Princeton, NJ: Princeton University Press.

Geuss, Raymond (2010). History and Illusion in Politics. Princeton, NJ: Princeton University Press.

Gray, John (1986). Liberalism. Milton Keynes: Open University Press. $2^{\text {nd }}$ edition 1995.

Gray, John (1989). Liberalisms: Essays in Political Philosophy. London: Routledge.

Gray, John (1993). Beyond the New Right: Markets, Government and the Common Environment. London: Routledge.

Gray, John (1995). Enlightenment's Wake: Politics and Culture at the Close of the Modern Age. London: Routledge.

Gray, John (1996). Isaiah Berlin. Princeton, NJ: Princeton University Press.

Gray, John (2000a). Two Faces of Liberalism. Cambridge: Polity Press.

Gray, John (2000b). "Pluralism and Toleration in Contemporary Political Philosophy." Political Studies 48: 323-333.

Hall, Edward (2013). Bernard Williams and the Basic Legitimation Demand: A Defence. Political Studies, doi: 10.1111/1467-9248.12070

Horton, John (2006). "John Gray and the Political Theory of Modus Vivendi". Critical Review of International Social and Political Philosophy 9: 155-69.

Horton, John (2010). "Realism, Liberal Moralism, and a Political Theory of Modus Vivendi". European Journal of Political Theory 9.

\footnotetext{
${ }^{33}$ I would like to thank to the editors of this volume, John Horton, Manon Westphal and Ulrich Willems, for their perceptive comments on this essay. The remaining errors are, naturally, mine.
} 
Jubb, Robert (2015). "The Real Value of Equality." The Journal of Politics, 77: 679-691.

Jubb, Robert, \& Rossi, Enzo (2015). "Political Norms and Moral Values". Journal of Philosophical Research, 40: 455-458.

Kekes, John (1993). The Morality of Pluralism. Princeton: Princeton University Press.

Kymlicka, Will (1989). Liberlalism, Community and Culture. Oxford: Clarendon Press.

Larmore, Charles (1998). The Morals of Modernity. Cambridge: Cambridge University Press.

Leiter, Brian (2005). “American Legal Realism". In The Blackwell Guide to Philosophy of Law and Legal Theory, W. Edmundson \& M. Golding, eds, London: Blackwell.

McCabe, David (2010). Modus Vivendi Liberalism: Theory and Practice. Cambridge: Cambridge University Press.

Newey, Glen (2001). "How Do You Like your Liberalism: Fat or Thin?". London Review of Books 23.

Rawls, John (1993). Political Liberalism. New York: Columbia University Press. $2^{\text {nd }}$ edition 1994.

Prinz, Janosch (2015). Raymond Geuss' radicalization of realism in political theory. Philosophy \& Social Criticism, DOI: $10.1177 / 0191453715583711$.

Prinz, Janosch, \& Rossi, Enzo (2017). "Political Realism as Ideology Critique". Critical Review of International Social and Political Philosophy, 20: 334-348.

Raekstad, Paul (2016). "Realism, Utopianism, and Radical Values." European Journal of Philosophy, forthcoming.

Rossi, Enzo (2008). "Liberal Democracy and the Challenge of Ethical Diversity". Human Affairs 18: 10-23.

Rossi, Enzo (2010). "Modus Vivendi, Consensus, and (Realist) Liberal Legitimacy." Public Reason, 2: 21-39.

Rossi, Enzo (2013). "Consensus, compromise, justice and legitimacy". Critical Review of International Social and Political Philosophy, 16: 557-572.

Rossi, Enzo \& Sleat, Matt (2014). "Realism in Normative Political Theory." Philosophy Compass, 9/10: 689-701.

Rossi, Enzo (2016). "Facts, Principles, and (Real) Politics." Ethical Theory and Moral Practice, 19: 505-520.

Sabl, Andrew (2017). "Realist Liberalism: An Agenda". Critical Review of International Social and Political Philosophy, 20: 349364.

Sagar, Paul (2014). "From Scepticism to Liberalism? Bernard Williams, the Foundations of Liberalism and Political Realism". Political Studies DOI: 10.1111/1467-9248.12173

Simmons, A. John (1999). "Justification and Legitimacy". Ethics 109: 739-771.

Waldron, Jeremy (1999). Law and Disagreement. Oxford: Oxford University Press.

Williams, Bernard (2005). In the Beginning Was the Deed: Realism and Moralism in Political Argument. Princeton, NJ: Princeton University Press. 